Supporting Information for:

\title{
Nanoporous Films with Photoswitchable Absorption Kinetics Based on Polymerizable Columnar Discotic Liquid Crystals
}

Jody A. M. Lugger ${ }^{1,2, \dagger}$, Patricia P. Marín San Román ${ }^{1, \dagger}$, Camiel C. E. Kroonen ${ }^{1}$, Rint P. Sijbesma ${ }^{1,2 *}$

${ }^{1}$ Laboratory of Supramolecular Polymer Chemistry, Department of Chemical Engineering and Chemistry, Eindhoven University of Technology, P.O. Box 513, 5600 MB Eindhoven, The Netherlands

2Institute for Complex Molecular Systems, Eindhoven University of Technology, P.O. Box 513, 5600 MB Eindhoven, The Netherlands

tThese authors contributed equally to this work.

*email: r.p.sijbesma@tue.nl 


\section{Table of Contents}

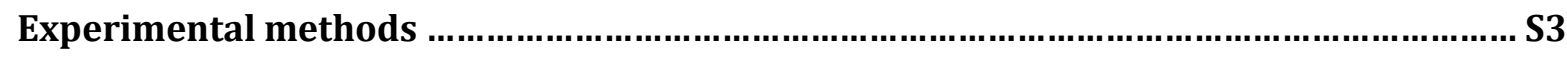

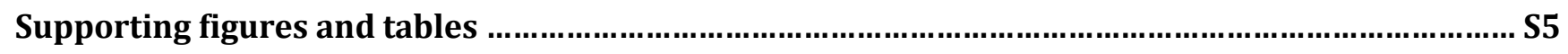

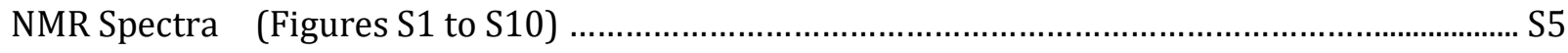

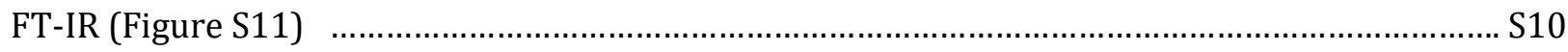

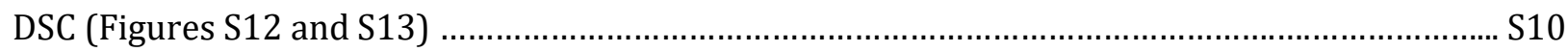

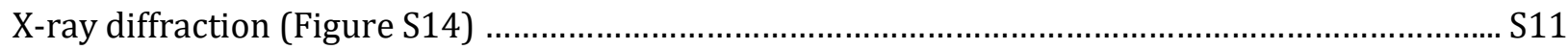

Half-Life time determination (Figures S15 and S16 and Table S1) …......................................... S12

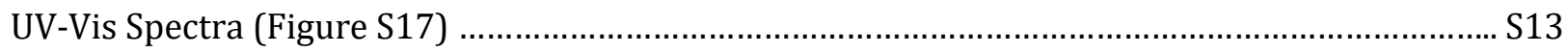

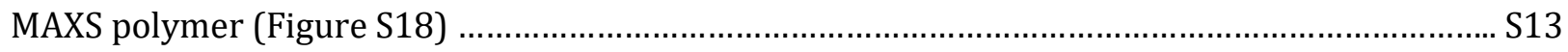

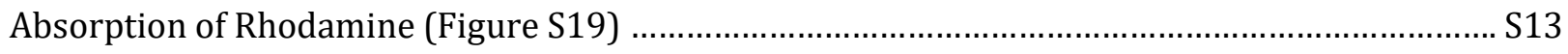




\section{Experimental methods}

\section{Methods-Sample preparations}

Clean glass substrates $(3 \times 3 \mathrm{~cm})$ were prepared by washing with acetone and isopropanol and finally dried. The nanoporous materials were made by making a solution of 4-((2,3,4-tris(undec-10-en-1-yloxy)phenyl)diazenyl)-benzoic acid 3 (3.2 equivalents) and 1,10-decanedithiol (4.8 equivalents) in $\mathrm{CHCl}_{3} / \mathrm{MeOH}(9: 1 \mathrm{v} / \mathrm{v})$ and adding this solution to the required amount of 1,3,5-tris(5-methyl-1H-benzo[d]imidazol-2-yl)benzene (MeTB, 1 equivalent) (50 mg mL-1). Finally, Bis(2,4,6-trimethylbenzoyl)-phenylphosphineoxide (Irgacure 819, $3 \mathrm{wt} \%$ ) was added as photo-initiator. $100 / 200 \mu \mathrm{L}$ of the solution was casted on a clean glass substrate of $3 \times 3 \mathrm{~cm}$ and spin coated at $2000 \mathrm{rpm}$ for 30 seconds. The temperature was then raised to $70^{\circ} \mathrm{C}$ and the sample was photo-polymerized using an EXFO Omnicure S2000 lamp with $8 \mathrm{~mW} / \mathrm{cm} 2$ of intensity, for 10 minutes, resulting in a bright orange non-soluble polymer. Then, the sample was placed in DMSO and shacked for $3 \mathrm{~h}$ to remove the template. Lastly, the DMSO was extracted and the sample was dried in a vacuum oven at $40^{\circ} \mathrm{C}$.

\section{Methods-UV-VIS switching experiment}

The photoinitiated switching between trans and cis was measured by making a solution of 3 in $10 \mathrm{~mL}$ chloroform (93.01 $\mu \mathrm{M})$. The UV-VIS spectrum was measured with a baseline set for chloroform. Trans to cis switching was measured by irradiating with $365 \mathrm{~nm}$ UV-light $(700 \mathrm{~mA})$ for respectively 5, 10, 15, 30, 60 seconds and measuring a new UV-VIS spectrum after each irradiation time. Cis to trans switching was measured by first irradiating the sample for 2 minutes with UV-light ( 365 $\mathrm{nm}$ ) and then irradiating the sample 5, 10, 15, 30 and 60 seconds with blue light of $450 \mathrm{~nm}(350 \mathrm{~mA})$ and measuring the UVVIS spectra.

The photo and back isomerization between trans and cis of the polymer were measured in solid state onto glass substrates via UV-VIS spectroscopy. The baseline is set for the clean glass. Trans to cis switching was measured by irradiating with 365 nm UV-light (700 mA) for $4 \mathrm{~h}$ and taking a new UV-VIS spectrum every 5, 10 or 20 minutes in the end due to the stabilization. Cis to trans back switching was measured by first irradiating the sample for 4 hours with UV-light ( $365 \mathrm{~nm}$ ) and then in the dark a spectrum was taken every 30 minutes for 9 hours.

\section{Methods-Cis to trans decay experiment}

Cis to trans decay experiments were performed by irradiating a solution of 3 (13.8 mg) in $\mathrm{CDCl}_{3}(0.7 \mathrm{~mL}) \mathrm{with} \mathrm{UV}$-light of $365 \mathrm{~nm}(700 \mathrm{~mA})$ for 5 minutes. Then a ${ }^{1} \mathrm{H}-\mathrm{NMR}$ was measured after $0,5,22$ and 27 hours. Integrals were compared to the single proton peak on the benzene ring.

\section{Half-life determination}

The graph data of Figure S15 was fitted with the equation for half-life (1):

$N(t)=N_{0} *(0.5)^{\frac{t}{t_{0.5}}}$

Where $\mathrm{N}(\mathrm{t})$ represents the amount of cis at time $=\mathrm{t}, \mathrm{N}_{0}$ the amount at $\mathrm{t}=0(3.92 \mathrm{mM}), \mathrm{t}$ the time $(\mathrm{h})$ and $\mathrm{t}_{0.5}$ represents the half-life time (h) at a specific temperature.

\section{Dye-Selectivity tests}

Measurements were done in a quartz cuvette and stirred at $400 \mathrm{rpm}$. Concentrations were calculated from the molar extinction coefficient of Rhodamine $6 \mathrm{G}$ at $474 \mathrm{~nm}$ using Lambert-Beer's Law in water. The mass of the films was weighed on a microbalance before the measurement. The volume was kept constant at $3 \mathrm{~mL}$. For absorption measurements, the initial concentration of the dye was $10 \mu \mathrm{M}(40 \mathrm{mg} / \mathrm{L})$ and the absorbance was measured every minute during $10 \mathrm{~h}$. Measurements were done upon time at room temperature for a sample before irradiation (trans isomer) and after irradiated with UV-light during 6 hours (cis isomer).

\section{Fickian diffusion model fitting}

Dye uptake for the full-time scale was directly fitted using the Fickian transport model (Equation 2), which correlates the absorption profile of the dye, in this case Rhodamine $6 \mathrm{G}$ in a single pore of the porous material with the decrease in concentration in solution. 


$$
C_{b}(t)=\int_{x=0}^{x=l / 2} C_{0}\left(1-\operatorname{erf} \frac{x}{\sqrt{4 \mathfrak{D}_{F} t}}\right) d x(2)
$$

With $\mathrm{C}_{\mathrm{b}}$ as concentration of the dye $(\mathrm{mg} / \mathrm{L})$ in the solution at $\mathrm{y}(\mathrm{t}) . \mathrm{c}_{\mathrm{o}}$ concentration dye at $\mathrm{t}(0), \mathrm{t}$ time $(\mathrm{s}), x$ the pore length $(\mathrm{um})$ and $\mathfrak{D}$ the absorption coefficient of the adsorbate.

Eq. 1 was fitted to the batch absorption curves obtained for the cis and the trans isomers (Figure S18) by applying a range of diffusion coefficients. The best fit value was determined by minimizing the sum $\mathrm{S}$ of absolute weighted difference between the measured and fitted data points (Eq. 3)

$$
S=\sum_{i=1}^{N}\left|\frac{\left(y_{i}-f\left(x_{i}\right)\right.}{y_{i}}\right|
$$

With $y_{i}$ as concentration of the dye $(\mathrm{mg} / \mathrm{L})$ in the solution at $\mathrm{t}, f\left(x_{i}\right)$ concentration dye calculated according to Eq.2, and $\mathrm{S}$ the sum of absolute weighted deviations between $f\left(x_{i}\right)$ and $y_{i}$

The fitting procedure was performed on a reduced number of data points (20 from initial 100) to shorten the fitting time. The equilibrium concentration of the dye $\left(\mathrm{C}_{\mathrm{eq}}\right)$ was obtained by extrapolating Eq. 2 to infinite time $\mathrm{cb}_{\mathrm{b}}(\mathrm{t}=\infty)$. Best fit for trans and cis isomers are presented in the report. 


\section{Supporting figures and tables}

\section{NMR Spectra}

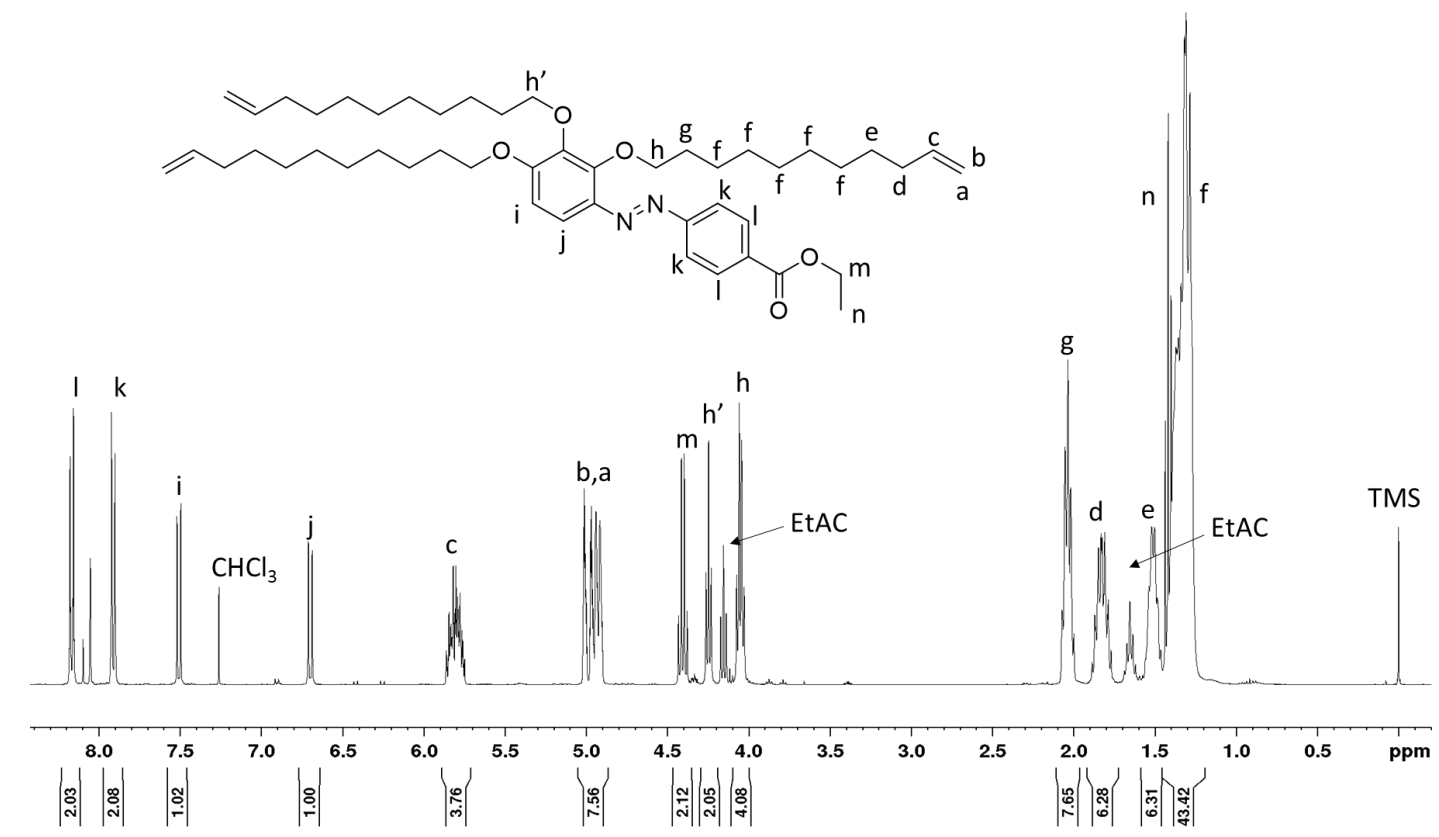

Figure S1. ${ }^{1} \mathrm{H}-\mathrm{NMR}$ spectrum of alkene ester 2 in $\mathrm{CDCl}_{3}$

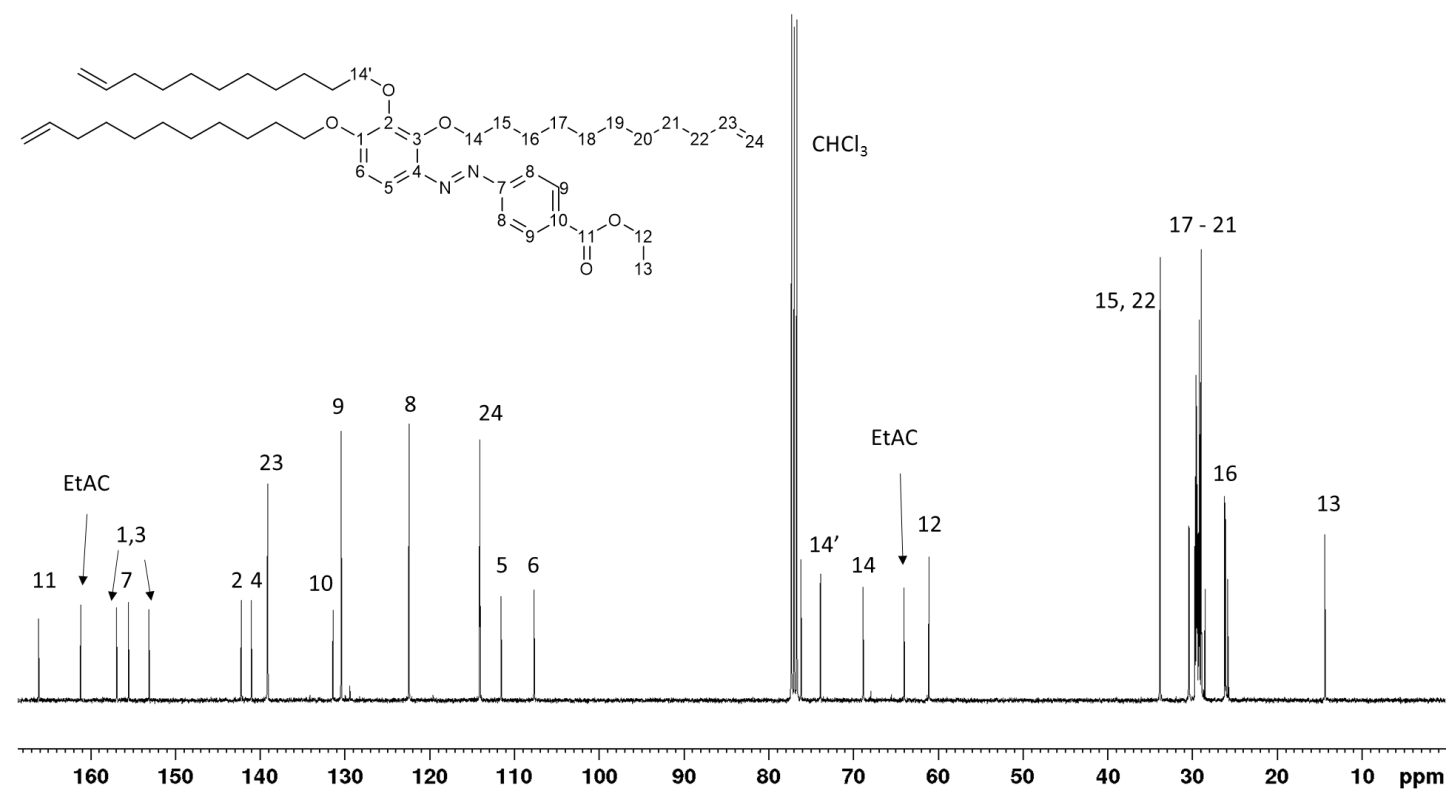

Figure S2: ${ }^{13} \mathrm{C}-\mathrm{NMR}$ spectrum of alkene ester $\mathbf{2}$ in $\mathrm{CDCl}_{3}$ 


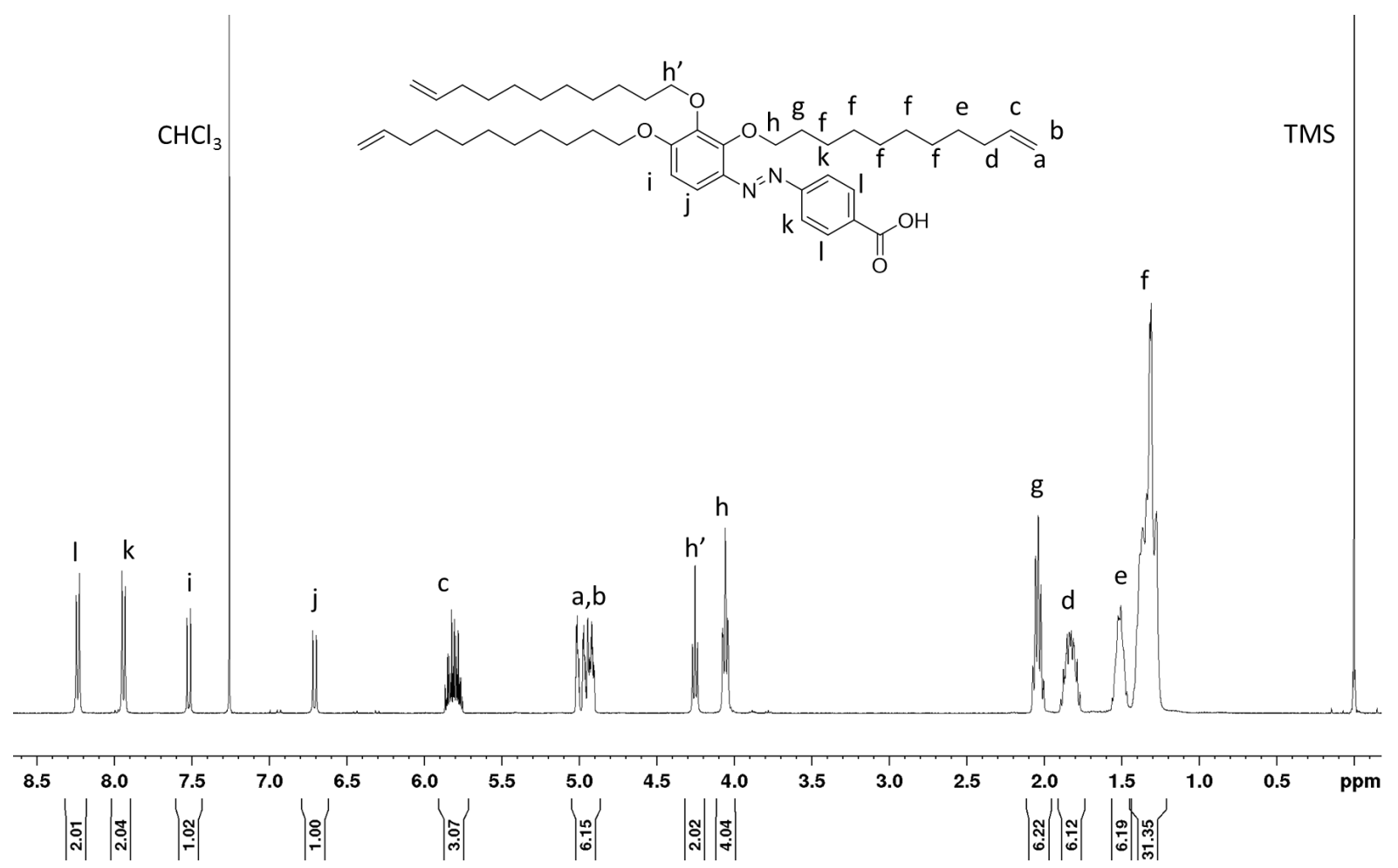

Figure S3. ${ }^{1} \mathrm{H}-\mathrm{NMR}$ spectrum of azobenzoic acid $\mathbf{3}$ in $\mathrm{CDCl}_{3}$

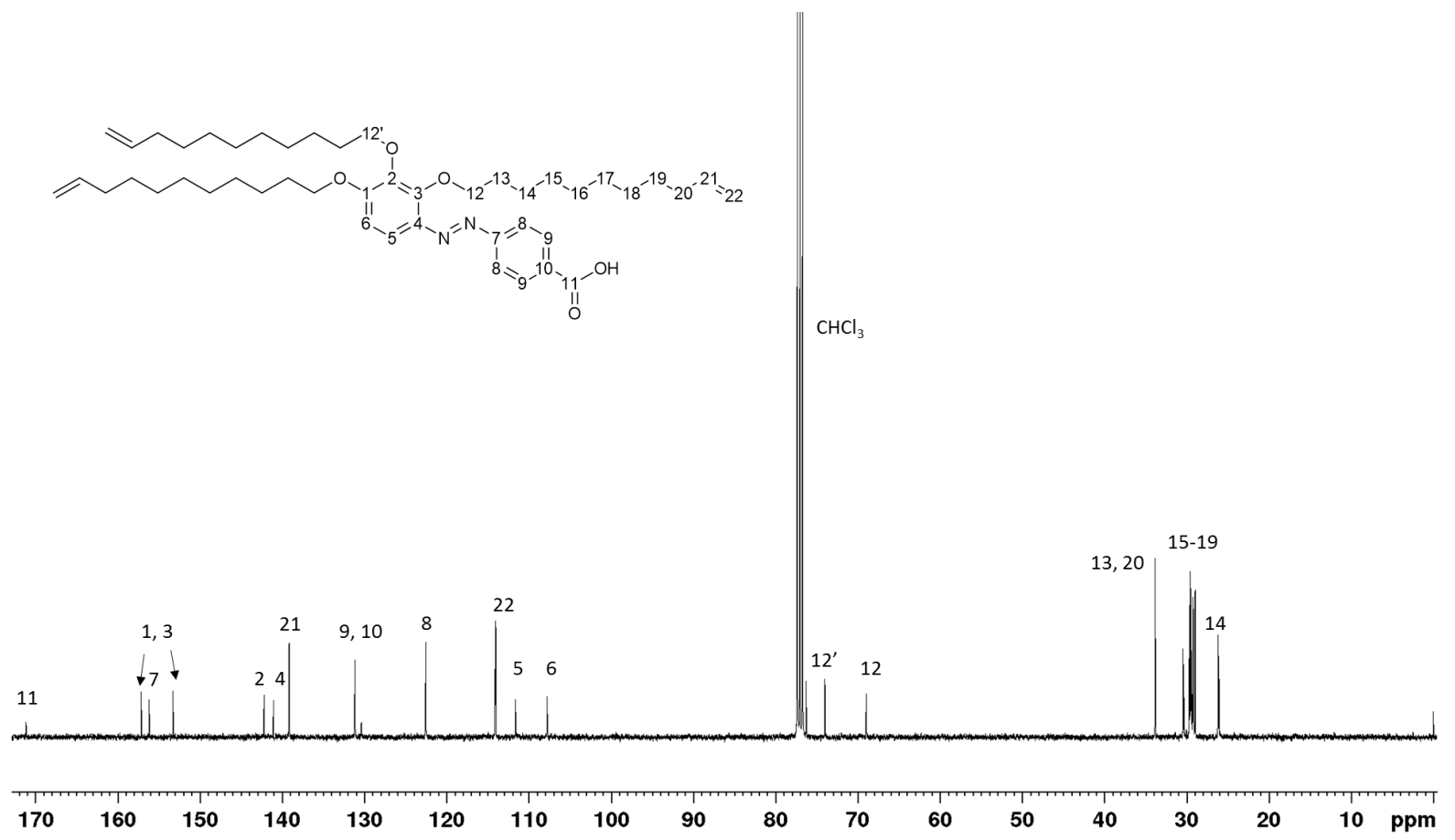


Figure S4: ${ }^{13} \mathrm{C}$-NMR spectrum of azobenzoic acid 3 in $\mathrm{CDCl}_{3}$

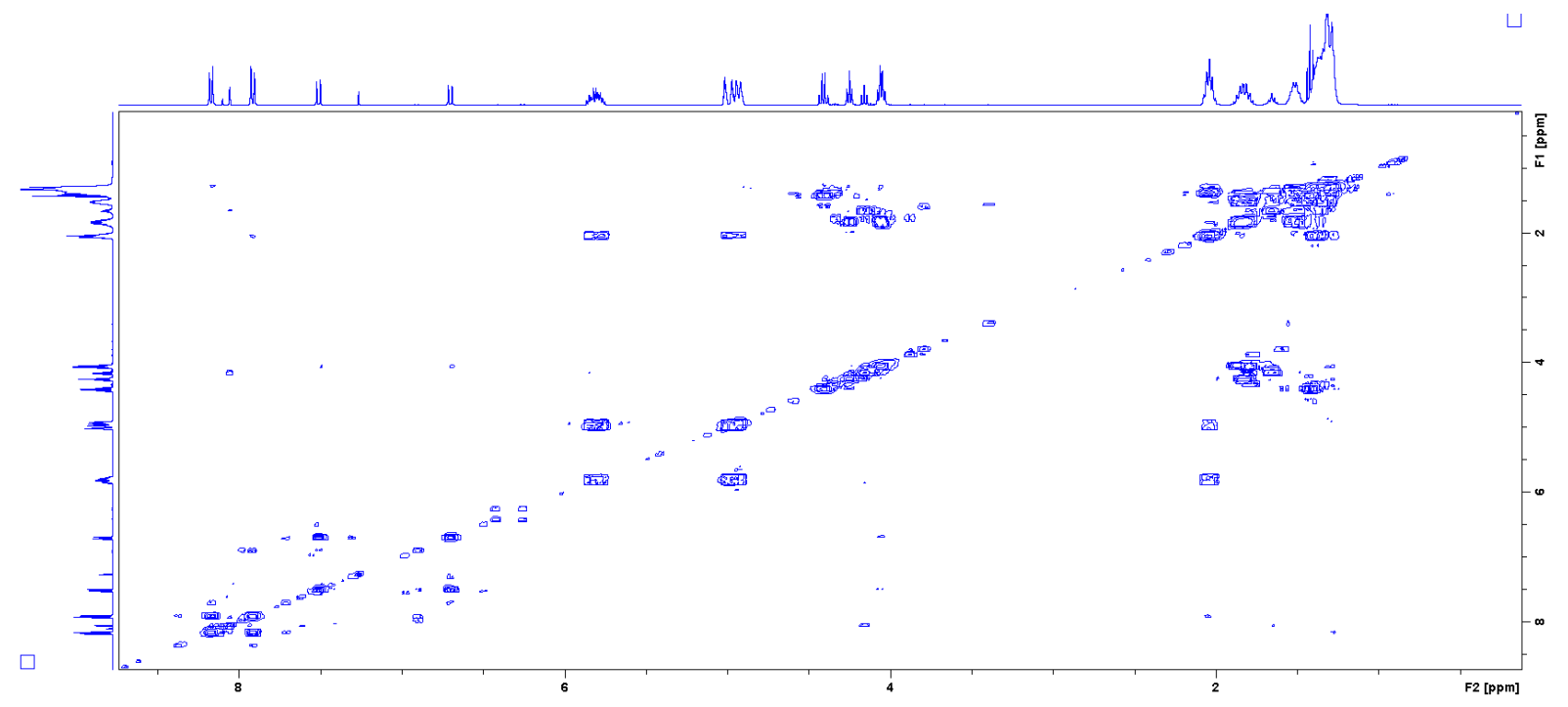

Figure S5. COSY spectrum of alkene ester 2 in $\mathrm{CDCl}_{3}$

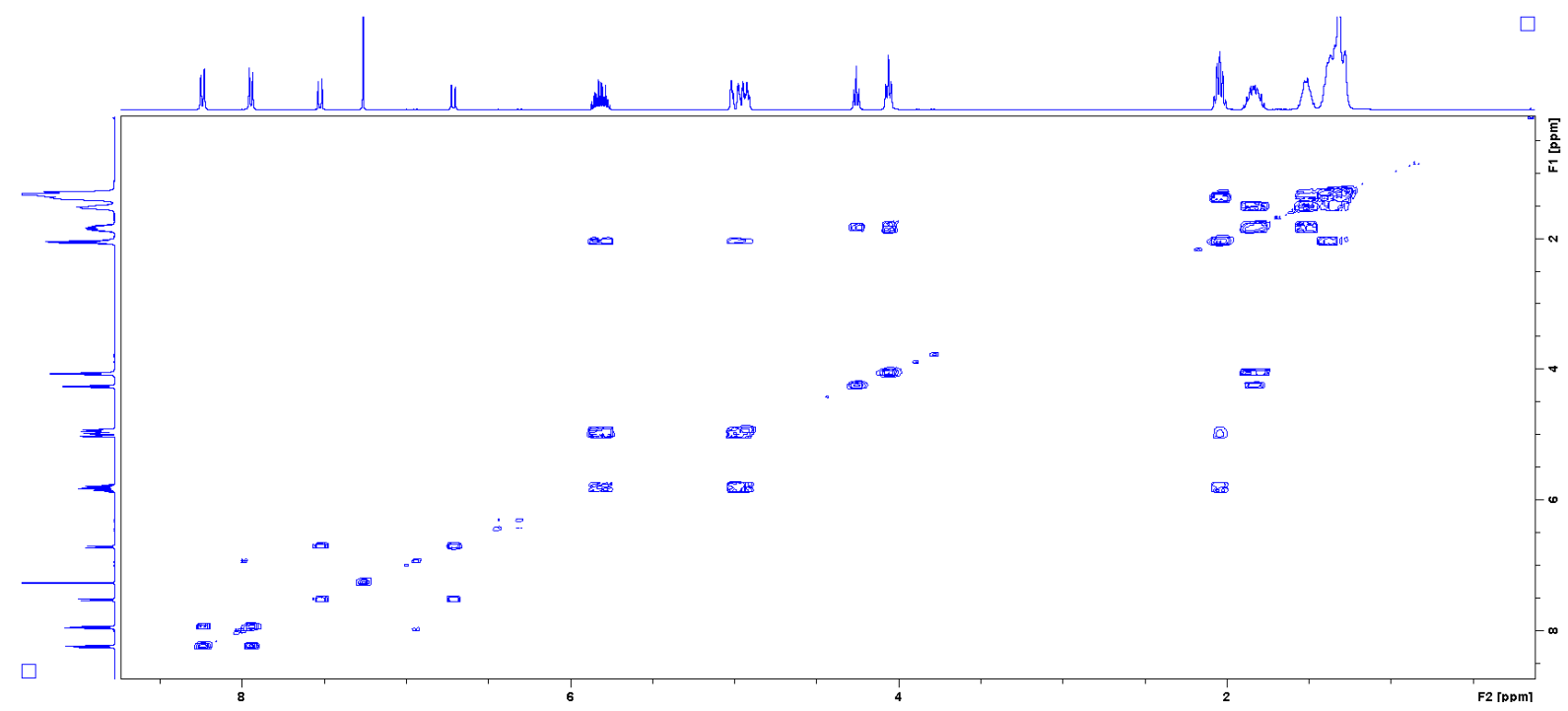


Figure S6. COSY spectrum of azobenzoic acid $\mathbf{3}$ in $\mathrm{CDCl}_{3}$

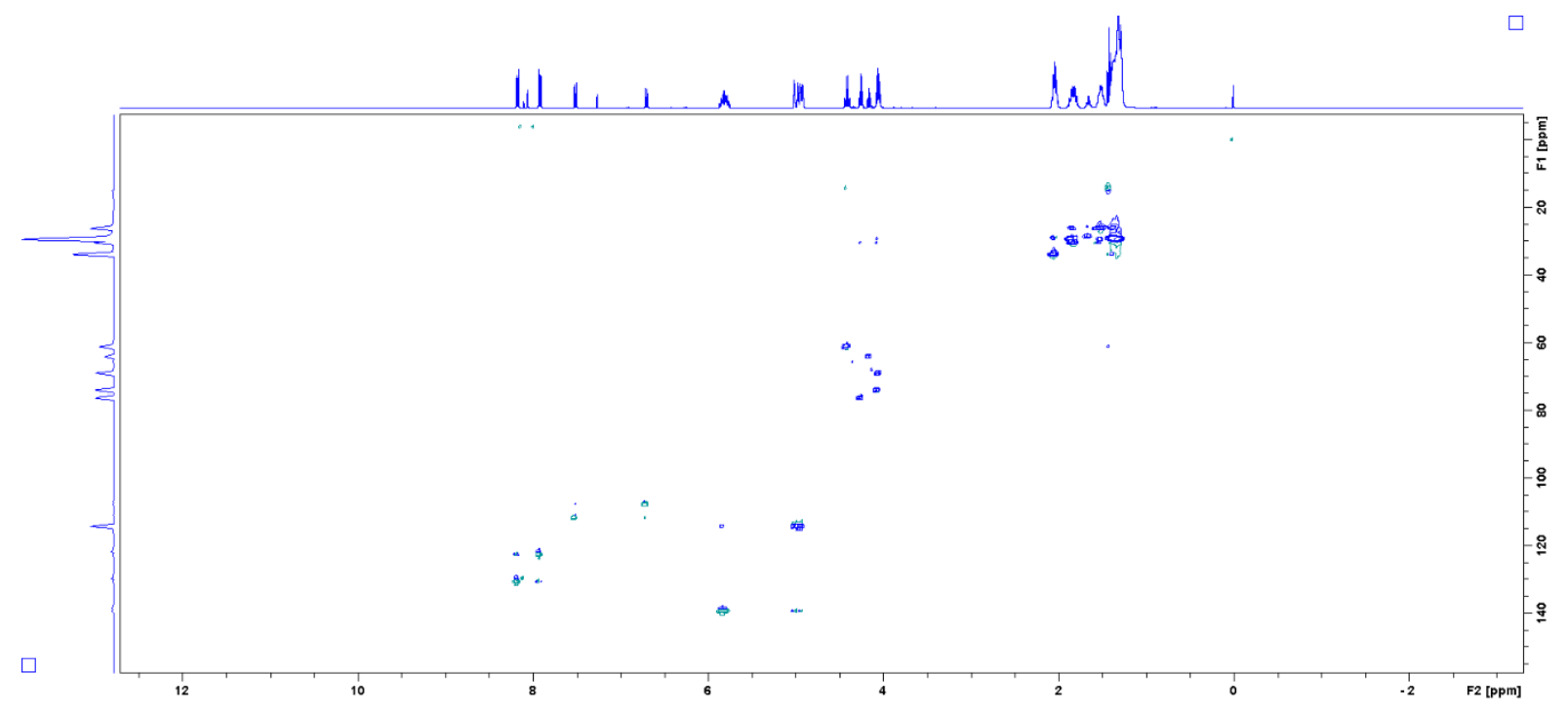

Figure S7: COSY spectrum of azobenzoic acid $\mathbf{3}$ in $\mathrm{CDCl}_{3}$

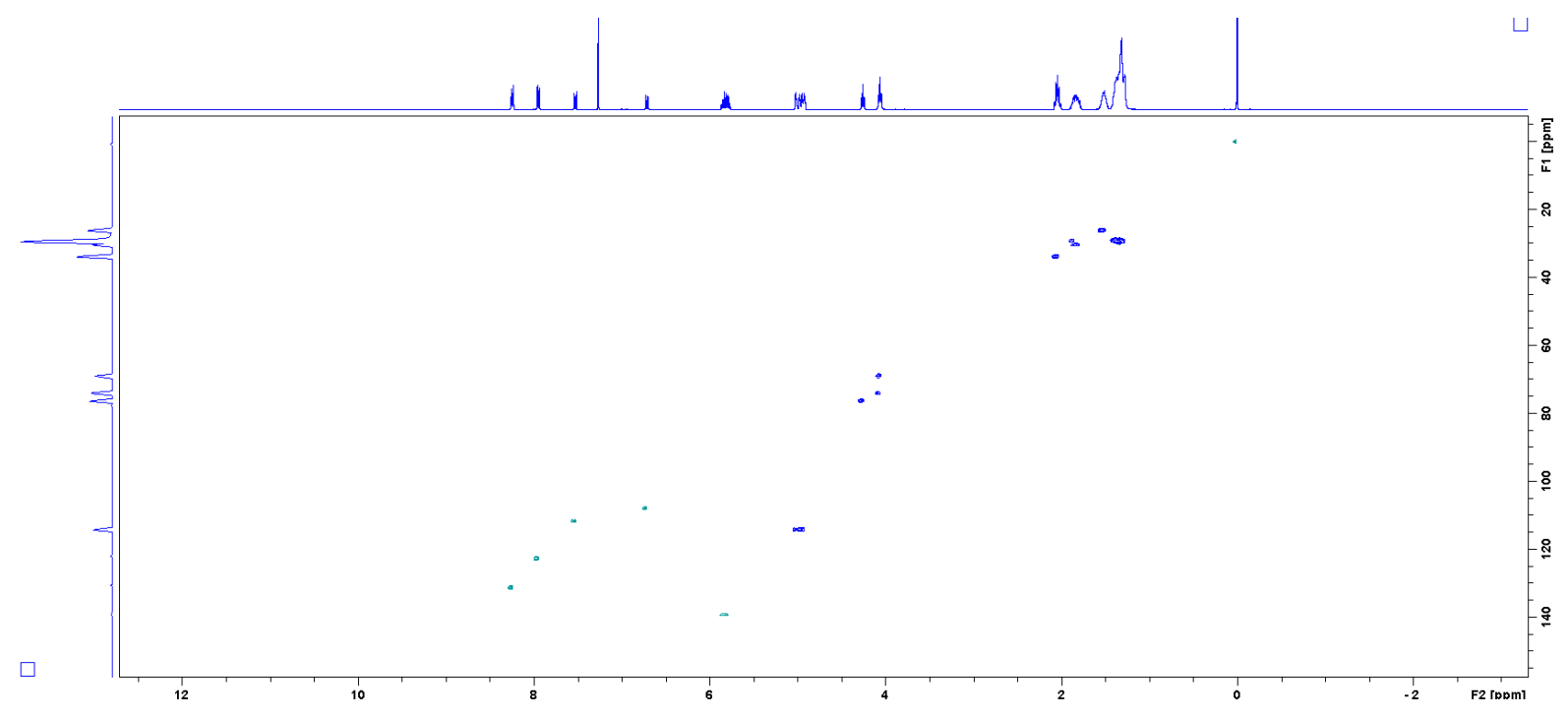

Figure S8. HSQC spectrum of azobenzoic acid $\mathbf{3}$ in $\mathrm{CDCl}_{3}$ 


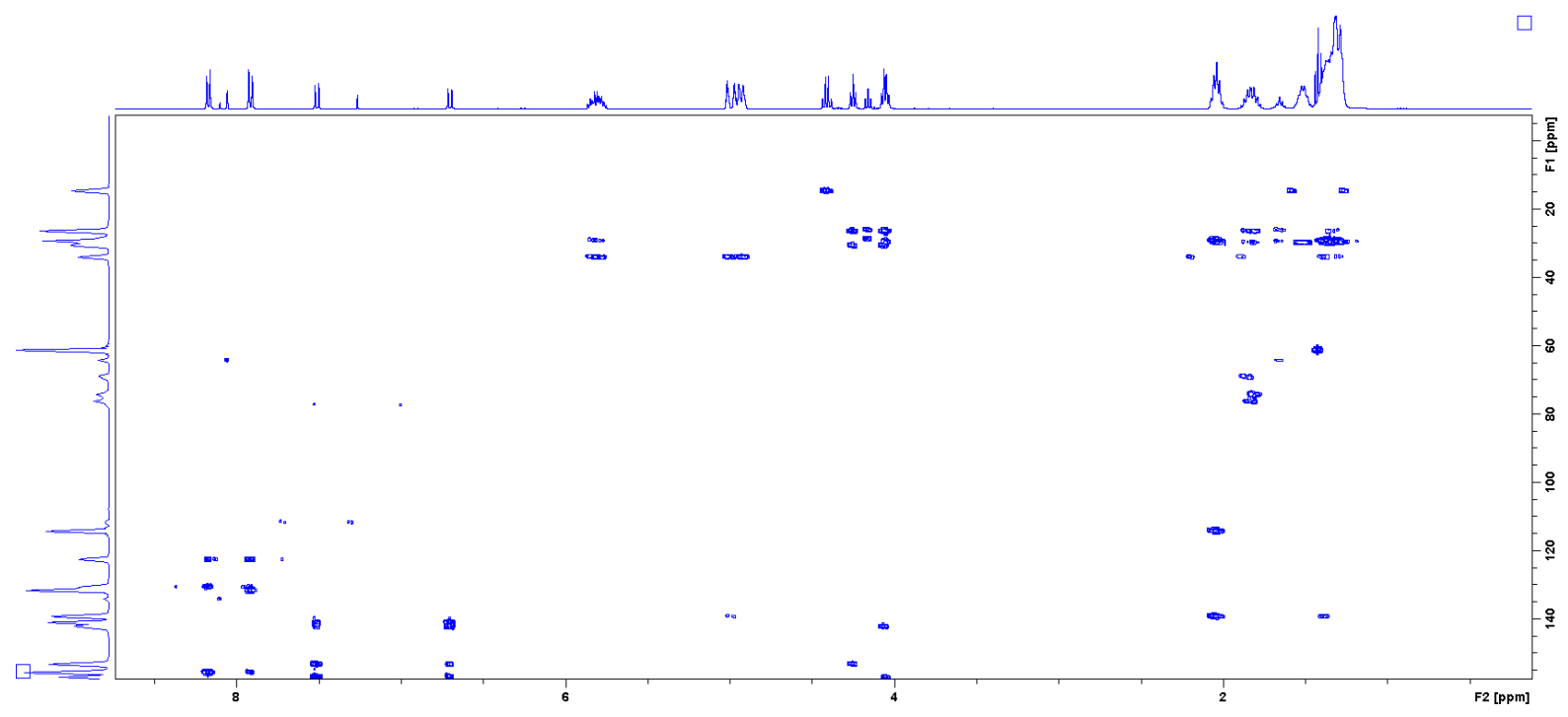

Figure S9. HMBC spectrum of alkene ester 2 in $\mathrm{CDCl}_{3}$

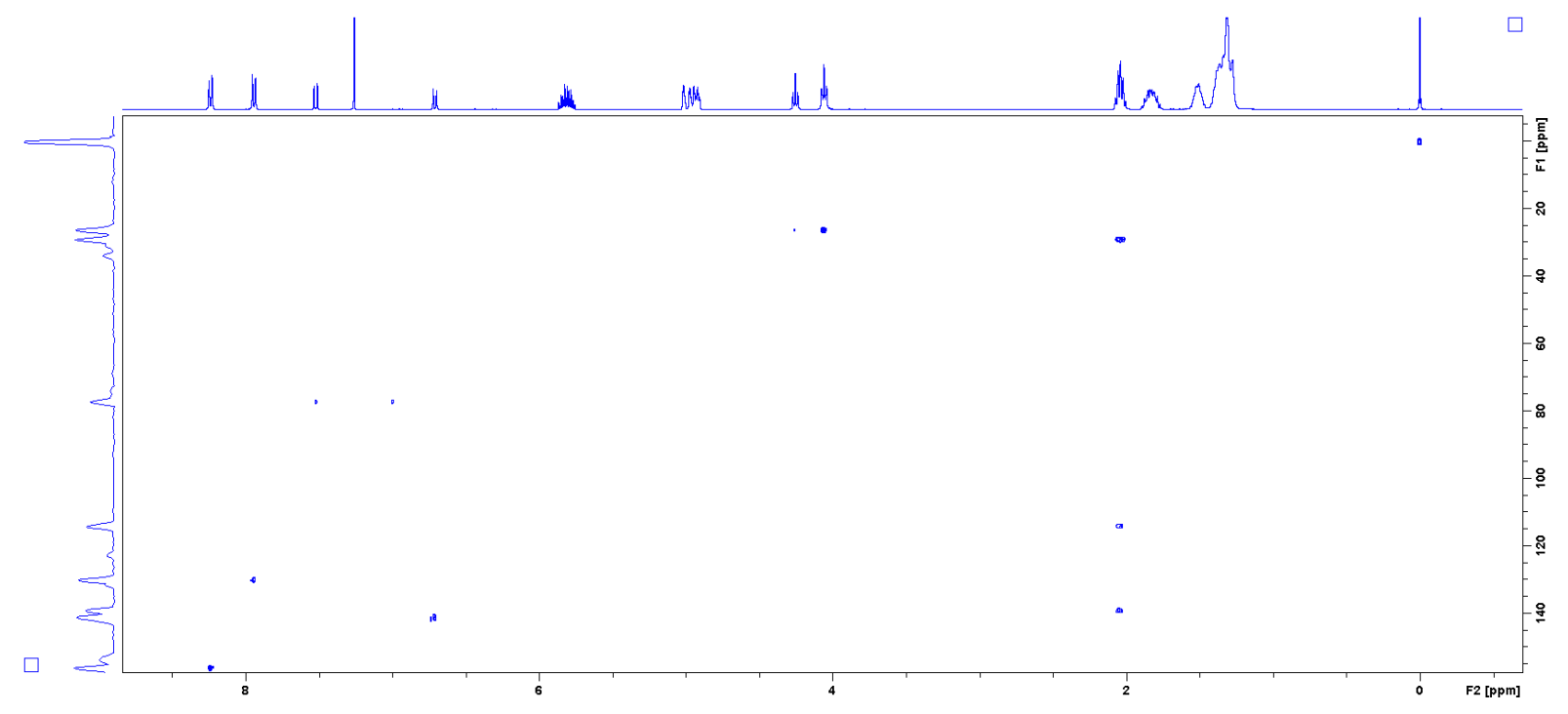

Figure S10. HMBC spectrum of azobenzoic acid 3 in $\mathrm{CDCl}_{3}$ 


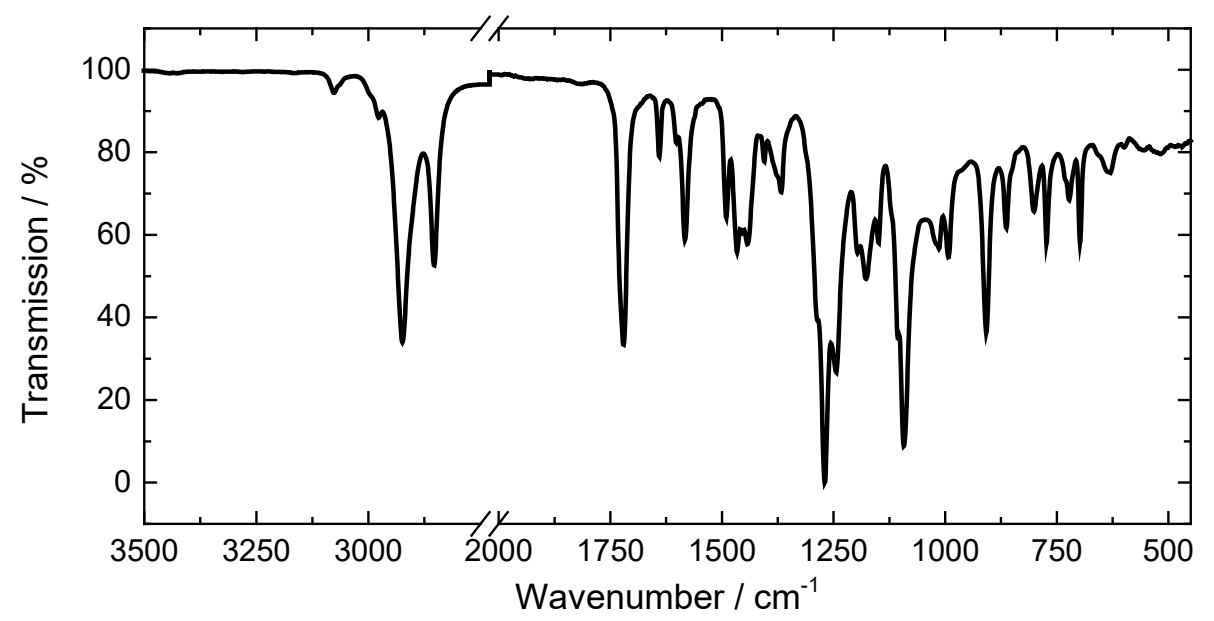

Figure S11. FT-IR spectrum of alkene ester 2

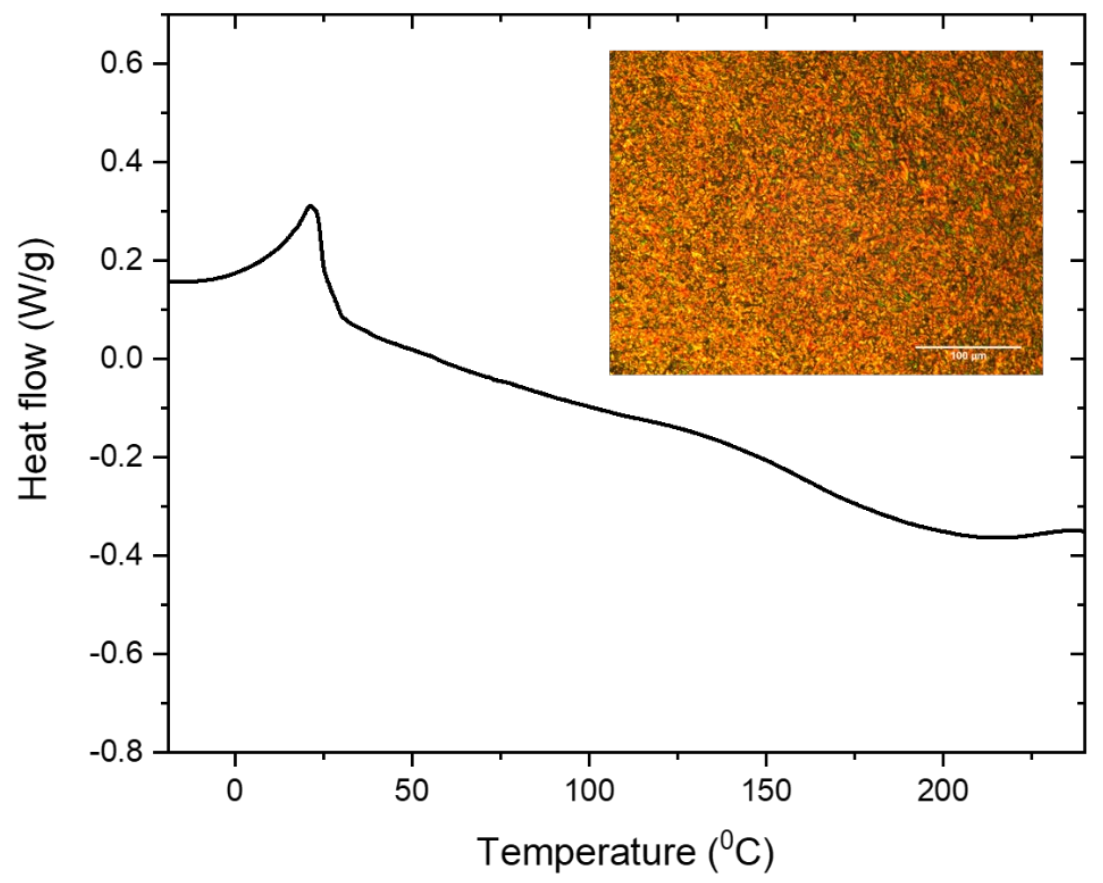

Figure S12. DSC trace and POM image of azobenzoic acid 3 at $75^{\circ} \mathrm{C}$ 


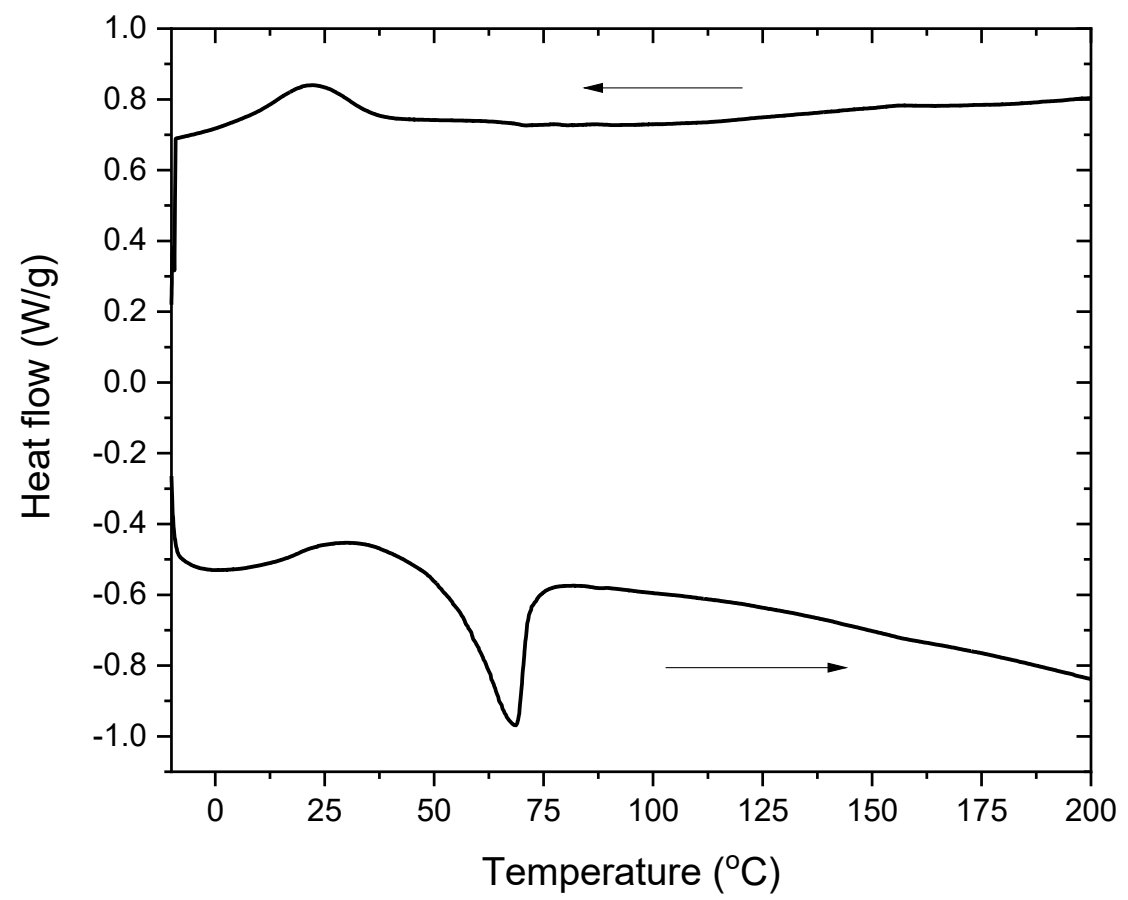

Figure S13. DSC $2^{\text {nd }}$ cycle of TB $\cdot \mathrm{Azoac}_{3}$ complex in a $3.2: 1$ mixture heating and cooling at $10^{\circ} \mathrm{C} / \mathrm{min}$
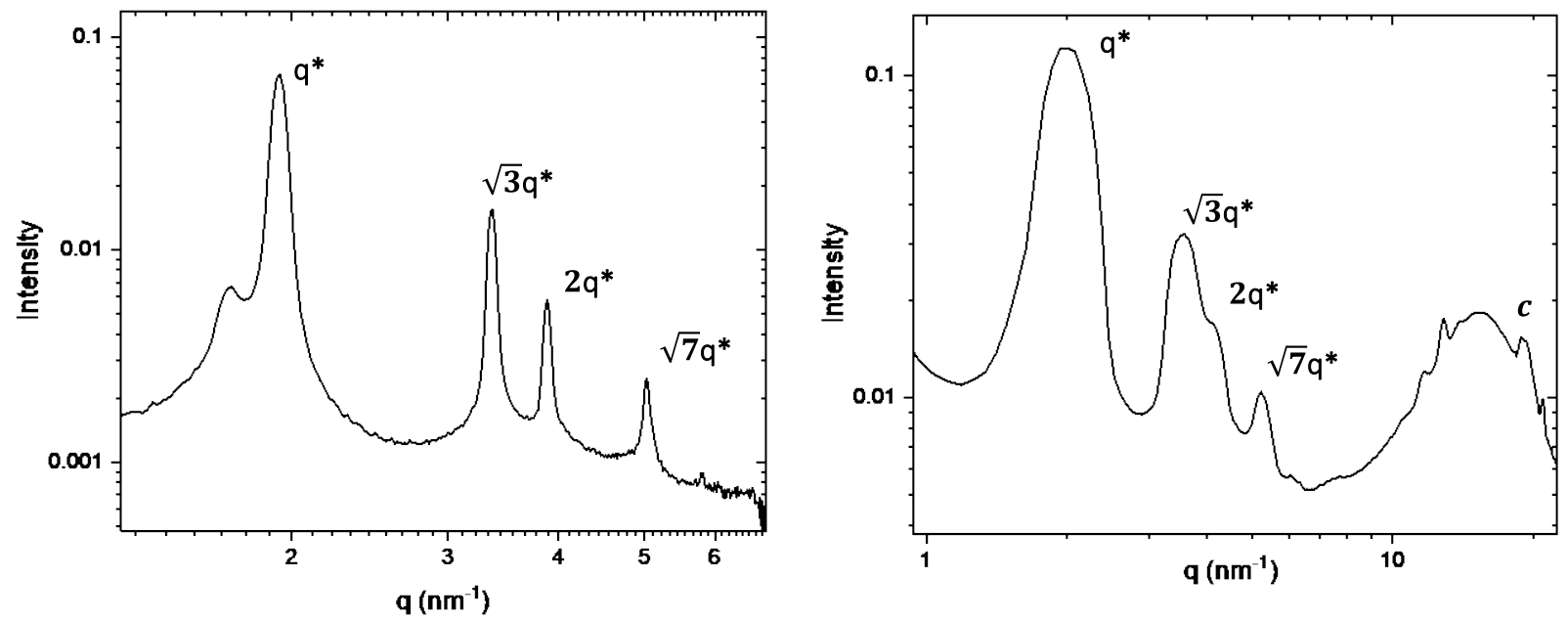

Figure S14. MAXS and WAXS diffractogram of complex TB·Azoac3 at RT. 

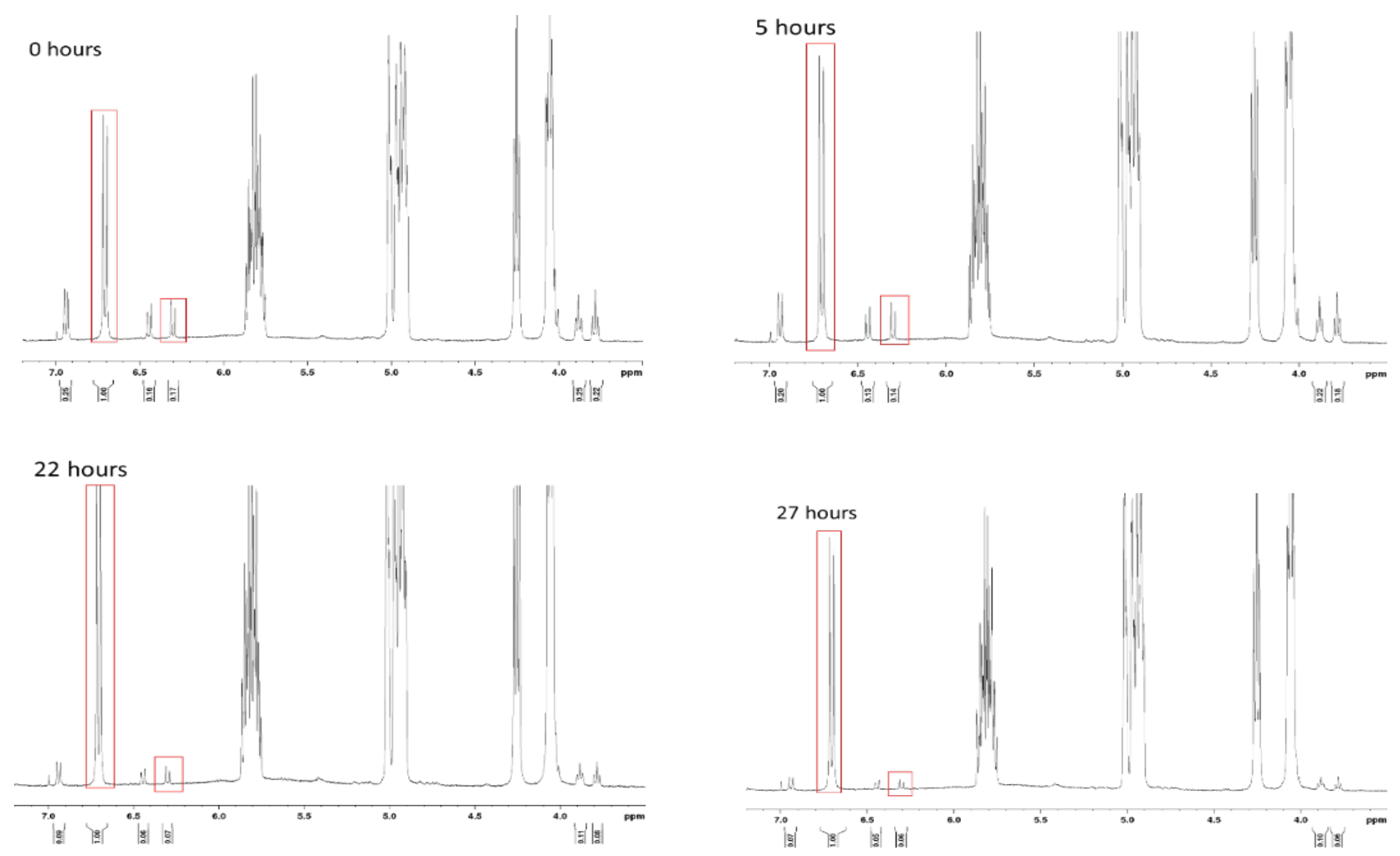

Figure S15. ${ }^{1} \mathrm{H}-\mathrm{NMR}$ spectra after 0, 5, 22 and 27 hours of thermal relaxation in $\mathrm{CDCl}_{3}$.

\begin{tabular}{c|c|c}
\hline Time $(\mathrm{h})$ & Area & Concentration $(\mathrm{mM})$ \\
\hline 0 & 0.17 & 3.92 \\
5 & 0.14 & 3.31 \\
22 & 0.07 & 1.76 \\
27 & 0.06 & 1.53 \\
\hline
\end{tabular}

Table S1: Area of ${ }^{1} \mathrm{H}-\mathrm{NMR}$ converted to concentrations after different relaxation times

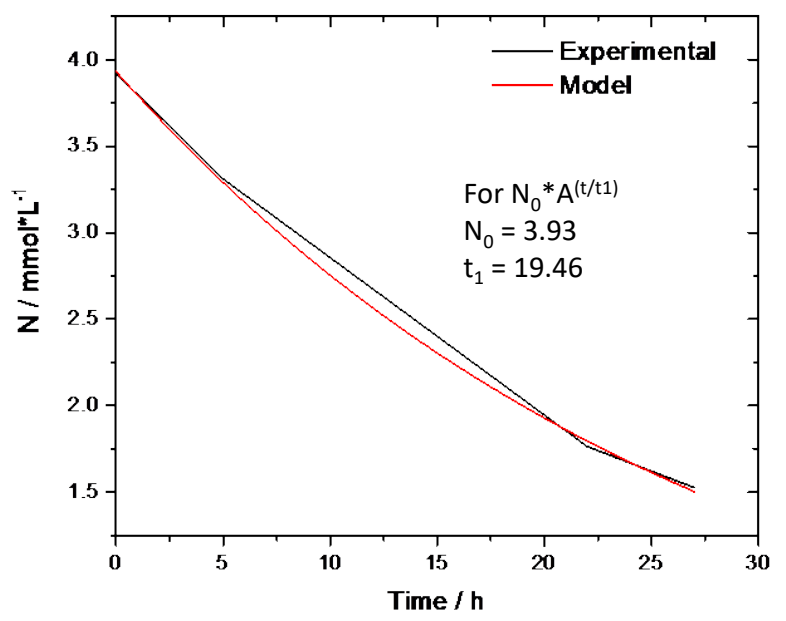

Figure S16. Plot of the concentration for the cis isomer at different relaxation times (black) and plot of the half-life time fitted model (red). 


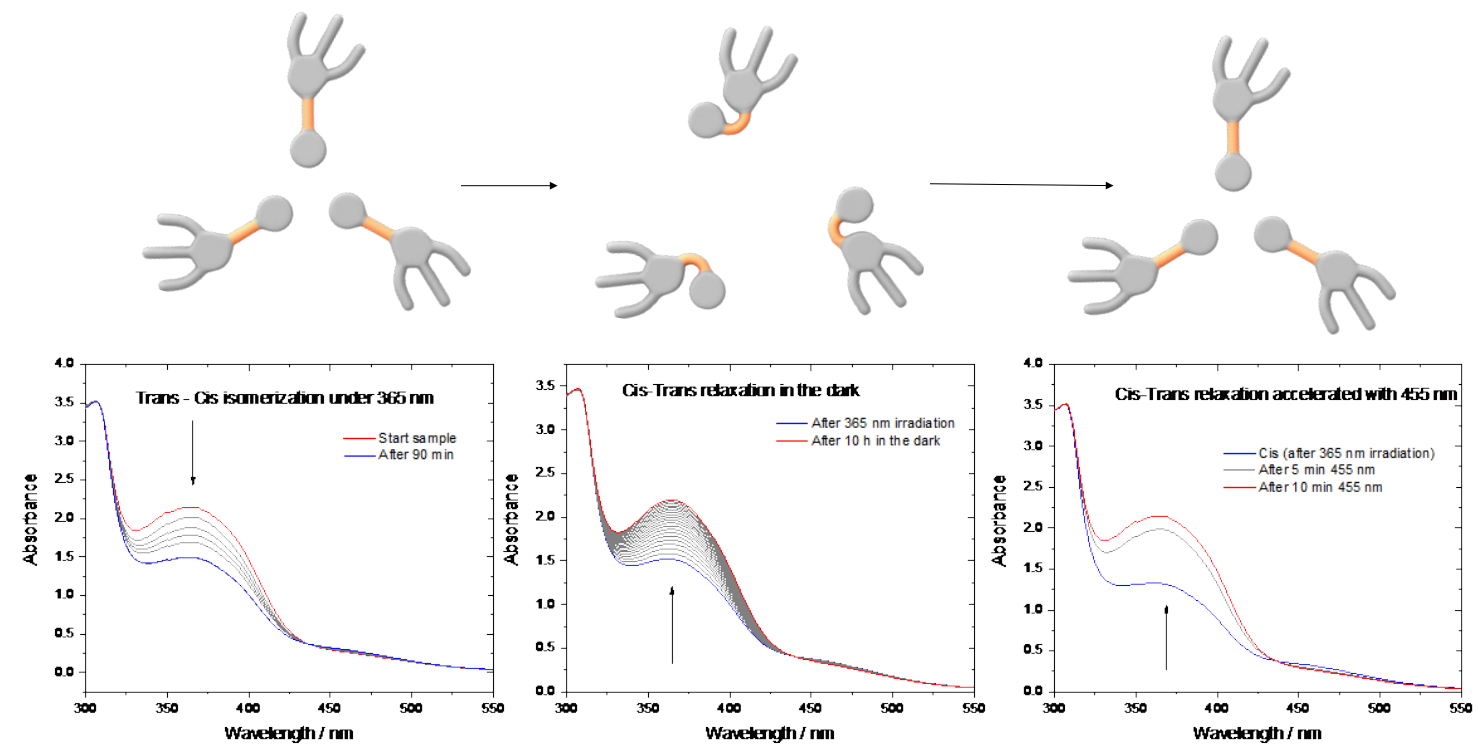

Figure S17: Cis-trans back-isomerization of the polymer accelerated using blue light of $455 \mathrm{~nm}$.

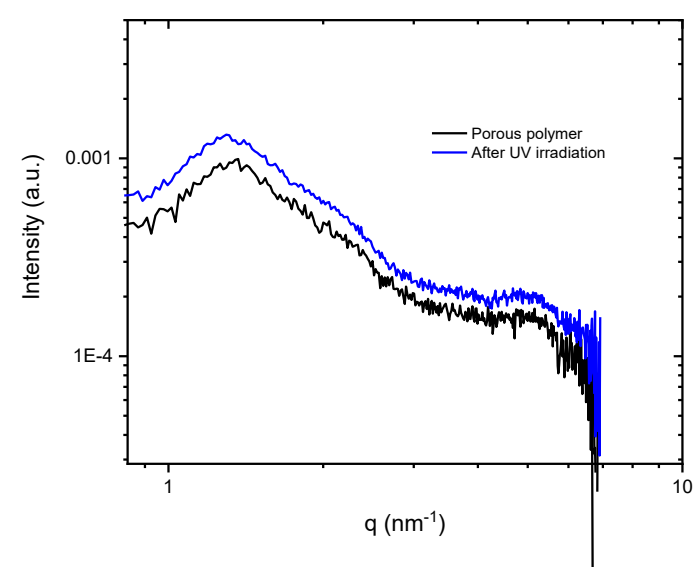

Figure S18: MAXS of the 3:1 polymer before and after UV irradiation corresponding to the Trans and Cis state respectively at room temperature.

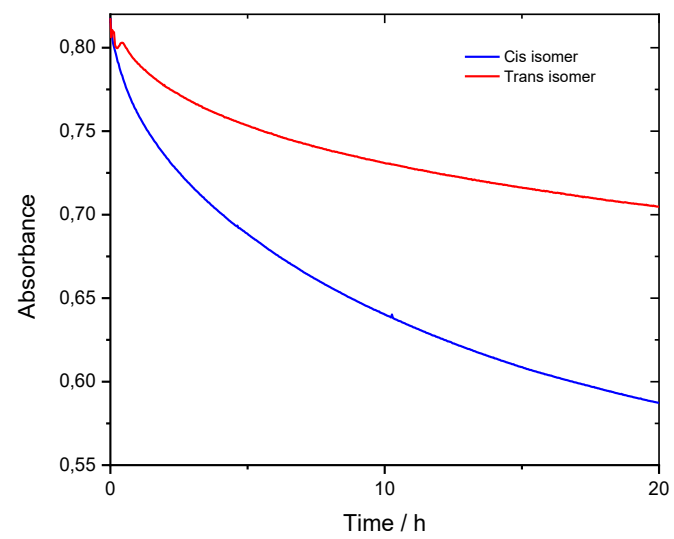

Figure S19: Plot of absorption Rhodamine 6G upon time for trans and cis porous polymers 
